ARTICLE

https://doi.org/10.1038/s41467-019-10292-z

\title{
Poly(bis-arylimidazoliums) possessing high hydroxide ion exchange capacity and high alkaline stability
}

Jiantao Fan', Sapir Willdorf-Cohen ${ }^{2}$, Eric M. Schibli ${ }^{3}$, Zoe Paula ${ }^{1}$, Wei Li ${ }^{1}$, Thomas J.G. Skalski ${ }^{1}$, Ania Tersakian Sergeenko ${ }^{1}$, Amelia Hohenadel ${ }^{1}$, Barbara J. Frisken (1D ${ }^{3}$, Emanuele Magliocca ${ }^{4}$, William E. Mustain ${ }^{4}$, Charles E. Diesendruck (iD ${ }^{5}$, Dario R. Dekel (10 ${ }^{2}$ \& Steven Holdcroft ${ }^{1}$

Solid polymer electrolyte electrochemical energy conversion devices that operate under highly alkaline conditions afford faster reaction kinetics and the deployment of inexpensive electrocatalysts compared with their acidic counterparts. The hydroxide anion exchange polymer is a key component of any solid polymer electrolyte device that operates under alkaline conditions. However, durable hydroxide-conducting polymer electrolytes in highly caustic media have proved elusive, because polymers bearing cations are inherently unstable under highly caustic conditions. Here we report a systematic investigation of novel arylimidazolium and bis-arylimidazolium compounds that lead to the rationale design of robust, sterically protected poly (arylimidazolium) hydroxide anion exchange polymers that possess a combination of high ion-exchange capacity and exceptional stability.

\footnotetext{
${ }^{1}$ Department of Chemistry, Simon Fraser University, 8888 University Drive, Burnaby, BC V5A 1S6, Canada. ${ }^{2}$ The Wolfson Department of Chemical Engineering, Technion-Israel Institute of Technology, Haifa 3200003, Israel. ${ }^{3}$ Department of Physics, Simon Fraser University, 8888 University Drive, Burnaby, BC V5A 156, Canada. ${ }^{4}$ Department of Chemical and Biomolecular Engineering, University of Connecticut, Storrs, Connecticut 06269, USA. ${ }^{5}$ Schulich Faculty of Chemistry, Technion-Israel Institute of Technology, Haifa 3200008, Israel. Correspondence and requests for materials should be addressed to S.H. (email: holdcrof@sfu.ca)
} 
A lkaline anion-exchange membranes (AAEMs) have gained attention due to their potential integration into a wide range of electrochemical energy storage and conversion technologies ${ }^{1-14}$. Anion-conducting polymers possess immobilized cationic groups that promote ion conduction but these same cations are the weak link in caustic media ${ }^{15-19}$. We have previously reported ${ }^{20}$ that the $o$-dimethylphenyl, C2-sterically protected benzimidazolium cation is more stable in basic environments than the phenyl-linked benzimidazolium analog due to enhanced steric hindrance around the C2benzimidazolium position, which serves to inhibit ring-opening degradation. $o$-Dimethylphenyl-protected benzimidazolium polymer analogs are stable in $2 \mathrm{M} \mathrm{KOH}$ at $60^{\circ} \mathrm{C}$ for extended periods ${ }^{20-22}$. Futhermore, Coates et al. ${ }^{23}$ reported enhanced alkaline stability of $o$-dimethylphenyl-protected imidazolium cations, and Fan et al. ${ }^{24}$ explored sterically protected polymeric analogs, reporting a poly(arylimidazolium) cationic polyelectrolyte that exhibited prolonged stability in $10 \mathrm{M} \mathrm{KOH}$ at elevated temperatures. Studies of the $o$-dimethylphenyl imidazolium model compound indicated that ring-opening degradation was greatly suppressed to the extent that the next available mode of degradation, dealkylation, became prominent. Investigating degradation pathways of poly(arylimidazoliums) under aggressive, caustic conditions, minimizing the dealkylation degradation pathway, while maintaining a high ion-exchange capacity (IEC) to promote anion conduction, is the focus in this paper. Developing an effective synthetic route for higher molecular weight poly(arylimidazoliums) in order to enhance their dimensional stability for the purpose of fabricating robust membranes is a second focus.

Based on density functional theory (DFT) calculations ${ }^{24}$, the computed free energies for degradation via ring-opening increases with the size of the protecting group around the $\mathrm{C} 2$ imidazolium position. However, among phenyl, o-dimethylphenyl, and $o$-diphenylphenyl C2-protected imidazoliums, the free energies for degradation via demethylation are similar, which indicates the sterically protecting groups around the $\mathrm{C} 2$ position exert negligible effect on this decomposition pathway. Bulky substituents attached to the N1/N3-imidazolium position may exert a stabilizing effect on the imidazolium cations. Coates et al. ${ }^{23}$ have shown that increasing the length of an alkyl chain at one of these positions enhances the stability of the imidazolium cation. Long et al. ${ }^{25}$ reported that for $n$-alkyltrimethyl ammonium cations the energy barrier for degradation via dealkylation increases from methyl to butyl.

In this work, various imidazolium and (bis)imidazolium cations are synthesized by alkylating corresponding imidazoles with different alkyl side chains and their stability to caustic conditions evaluated. The results are used to down select optimal cationic functionalities for the synthesis of poly(arylimidazolium) analogs that lead to robust, sterically protected poly(arylimidazolium) hydroxide anion exchange membranes that possess high IEC and exceptional stability under highly caustic conditions.

\section{Results}

Suppressing dealkylation of methylated imidazolium. Six imidazolium model compounds 9-14 possessing steric-protecting groups at the $\mathrm{C} 2$ position and different alkyl side chains attached to the N1/N3 imidazole position were synthesized. The half-life of these in $3 \mathrm{M} \mathrm{NaOD}$ at $80^{\circ} \mathrm{C}$ are shown in Fig. 1, together with the half-life of previously reported ammonium cations and benzimidazolium cations, shown for comparison. Compound 1, the most widely studied quaternary ammonium (QA) cation, degraded to $50 \%$ of its original amount within $180 \mathrm{~h}$ via demethylation and debenzylation. In the absence of the phenyl ring, compounds
2 and 3 are substantially longer-lived (half-lives of 1420 and 2080 h, respectively). Hibbs ${ }^{26}$ reported membranes comprising a poly (phenylene) backbone with compounds $\mathbf{1}$ and $\mathbf{2}$ attached as pendent cationic groups that exhibit $33 \%$ and $5 \%$ loss in conductivity over 14 days in $4 \mathrm{M} \mathrm{KOH}$ at $90^{\circ} \mathrm{C}$, respectively. Our previous studies of benzimidazoliums cations 4, 5, and 6 demonstrated increasing stability of the C2 substituent: phenyl < $o$-dimethylphenyl $<o$-diphenylphenyl (half-lives of $<0.1,436$ and $3240 \mathrm{~h}$, respectively) ${ }^{27}$. The stability of the corresponding three polymers showed a similar trend in stability, i.e., rapid degradation (minutes) in $0.3 \mathrm{M} \mathrm{KOH}$ at $25^{\circ} \mathrm{C}^{20}, 8 \%$ degradation after $168 \mathrm{~h}$ in $1 \mathrm{M} \mathrm{KOH}$ at $80^{\circ} \mathrm{C}^{22}$, and $5 \%$ degradation after $168 \mathrm{~h}$ in $2 \mathrm{M} \mathrm{KOH}$ at $80^{\circ} \mathrm{C}^{27}$, respectively. The major degradation pathway, illustrated in Fig. 2e, evolved from ring-opening for $\mathbf{4}$ and $\mathbf{5}$ to both ring-opening and demethylation for $\mathbf{6}$, and is supported by DFT calculations, which show that increased steric crowding at the $\mathrm{C} 2$ position raises the energy barrier for ring-opening degradation. Imidazolium cations 7 and $\mathbf{8}$ exhibit enhanced stability compared with benzimidazolium cations 4 and 5. Compound 7 degraded by both ring-opening and dealkylation, whereas compound $\mathbf{8}$ degraded solely by the dealkylation pathway $^{24}$.

Given these correlations, we focused efforts on suppressing dealkylation of imidazolium by utilizing longer alkyl side chains attached to the N1/N3 position. Compound 9, with its longer alkyl chains, was found to be significantly more stable $\left(t_{1 / 2}>\right.$ $10,000 \mathrm{~h}$ ) than 8 (dimethyl). No degradation of $\mathbf{9}$ was observed by nuclear magnetic resonance (NMR) spectroscopy after 10 days (Fig. 2a-d), which not only supports that dealkylation has been suppressed but also indicates that Hoffman elimination (potentially due to the presence of $\beta$-hydrogens) is absent. However, a consequence of attaching longer chains at the $N$-position is that the molecular weight of the repeat unit increases and hence the charge per mass ratio of the molecule decreases, which may adversely affect ionic conductivity of membranes prepared therefrom. A consequence of introducing two $n$-butyl groups at the expense of two methyl groups, e.g., is that the IEC of $\mathbf{9}$ and thus the maximum IEC of polymers prepared form 9 is limited to $2.13 \mathrm{mmol} \mathrm{g}^{-1}$ (reduced from $2.6 \mathrm{mmol} \mathrm{g}^{-1}$, dimethyl). To counter this, we prepared bis-imidazolium cations 10-14 for which the charge per mass is higher, as indicated in Fig. 1. The IEC of bis-imidazolium cations $\mathbf{1 0 - 1 4}$ are in the range 3.02-2.41 $\mathrm{mmol} \mathrm{g}^{-1}$ compared with $2.60-2.13 \mathrm{mmol} \mathrm{g}^{-1}$ for imidazoliums $\mathbf{8}$ and $\mathbf{9}$. However, it is found that the proximity of the second imidazolium cation in $\mathbf{1 0}$ lowers its stability compared with the analogous single imidazolium cation $\mathbf{8}$. This can be explained by the higher electrostatic potential (ESP), illustrated in Fig. 3a. The ESP around the imidazolium cation $\mathbf{1 0}$ is $0.226 \mathrm{eV}$, compared with $0.148 \mathrm{eV}$ for compound 8, which suggests that the electrostatic attraction between the cation and hydroxide anion is stronger, and may lead to more rapid attack of hydroxide on the imidazolium. A difference in the dihedral angles between the imidazolium and C2-phenyl might also play a role ${ }^{20}$; however, the dihedral angles of $o$-dimethylphenyl and imidazolium ring for 10 and $\mathbf{8}$ are similar $\left(82^{\circ}\right.$ vs. $\left.79^{\circ}\right)$ so this explanation may be ruled out. Indirect experimental evidence that a second imidazolium placed in close proximity increases the localized positive charge density of the molecule is drawn from the observation that complete alkylation ( $100 \%$ methylation) of the precursor of compound $\mathbf{1 0}$ to form the doubly charged molecule is synthetically much more difficult than alkylation to form the singly charged species (i.e., $75 \%$ alkylation). For example, $75 \%$ alkylation of the precursor to compound $\mathbf{1 0}$ (i.e., single cation formation) can be accomplished at room temperature but further alkylation to the double cation requires much higher temperatures and pressurized conditions. This observation is also 
Half lives of model compounds in $3 \mathrm{M} \mathrm{NaOD} / \mathrm{D}_{2} \mathrm{O} / \mathrm{CD}_{3} \mathrm{OD}$ at $80^{\circ} \mathrm{C}$

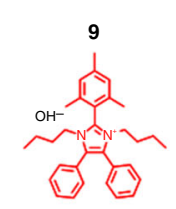

$>10,000 \mathrm{~h}$
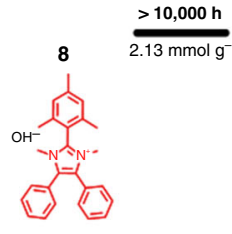

$\frac{7790 \mathrm{~h}}{260 \mathrm{mmol}^{-1}}$

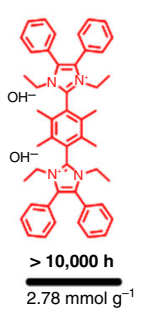<smiles>c1ccc2ccccc2c1</smiles>

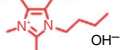

10

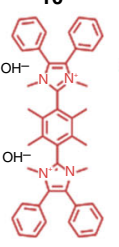

$2330 \mathrm{~h}$

$\frac{2330 \mathrm{~h}}{3.02 \mathrm{mmol} \mathrm{g}^{-1}}$
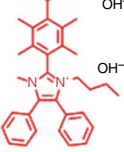

$5830 \mathrm{~h}$

$2.68 \mathrm{mmol} \mathrm{g}^{-1}$

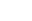

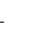

(1)

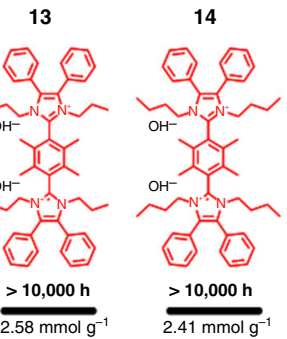

14
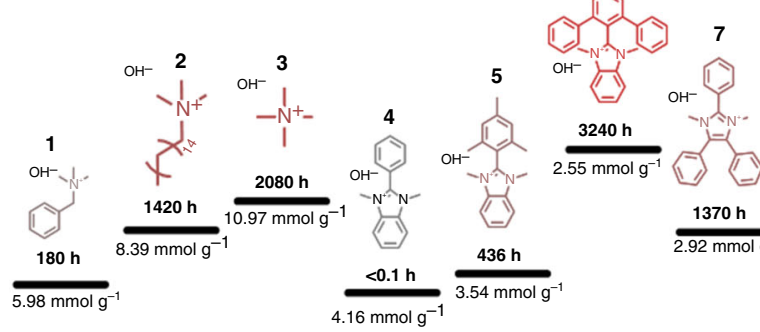

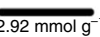

$2.58 \mathrm{mmol} \mathrm{g}^{-1}$

$2.41 \mathrm{mmol} \mathrm{g}^{-1}$

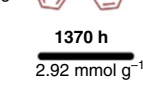

Fig. 1 Half-lives of cationic groups in $3 \mathrm{M} \mathrm{NaOD} / \mathrm{D}_{2} \mathrm{O} / \mathrm{CD}_{3} \mathrm{OD}$. Half-lives of six novel imidazolium cations $\mathbf{9 - 1 4}$ prepared for this work, along with ammonium cations ${ }^{24} \mathbf{1 - 3}$, and previously published benzimidazolium cations ${ }^{27} \mathbf{4 - 6}$ and imidazolium cations ${ }^{24} \mathbf{7 - 8}$. All model compounds were studied as $0.02 \mathrm{M}$ solutions in $3 \mathrm{M} \mathrm{NaOD}$ containing $7: 3 \mathrm{wt} . \mathrm{CD}_{3} \mathrm{OD}: \mathrm{D}_{2} \mathrm{O}$ at $80^{\circ} \mathrm{C}$. The water to ion ratio (hydration level), $\lambda$, is 4.8 . Half-lives $\left(t_{1 / 2}\right)$ of compounds 9-14 are estimated from data reported in Supplementary Figs. 1-12. The hydroxide ion-exchange capacity is provided

a

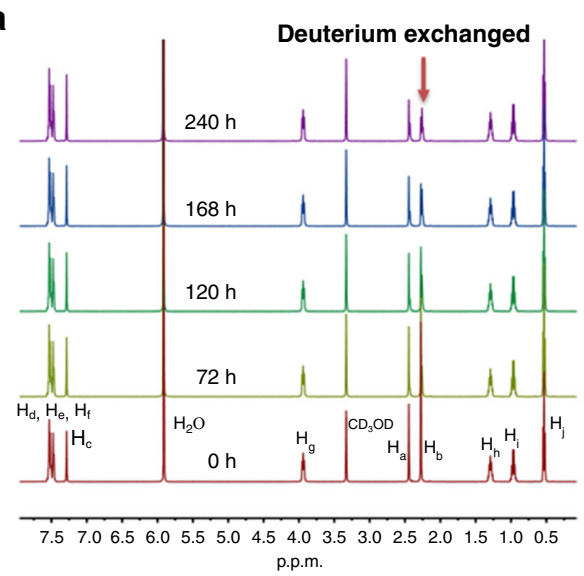

b

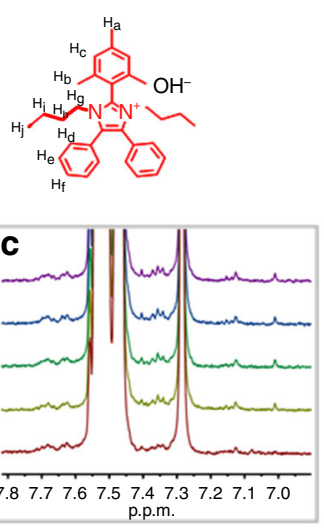

d
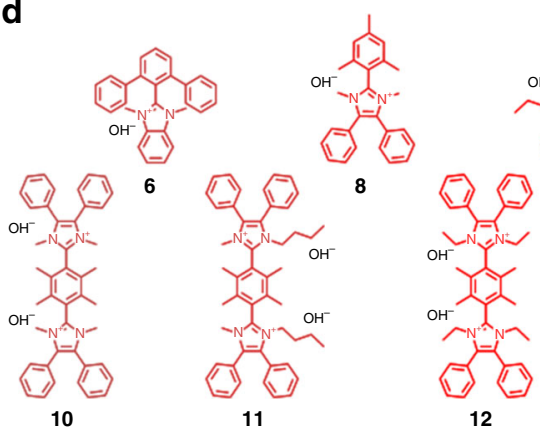

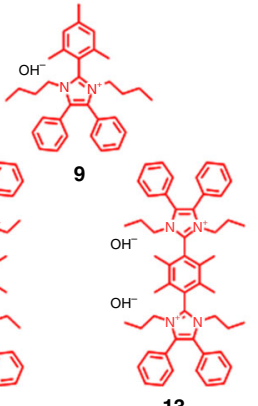

13

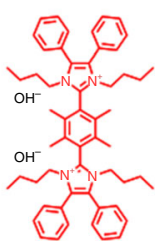

14

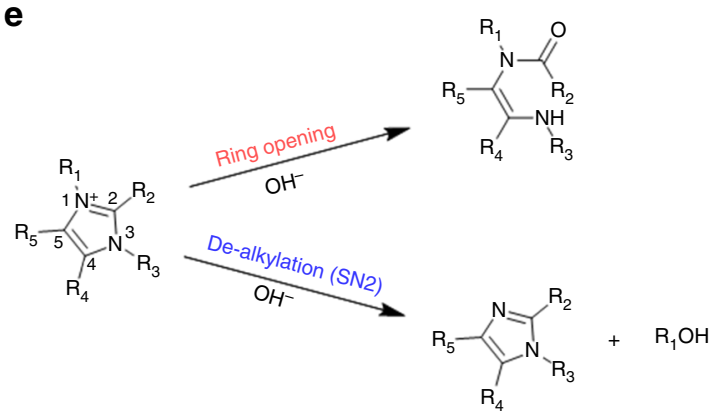

$R_{1}, R_{2}, R_{3}, R_{4}, R_{5}$, = alkyl or phenyl

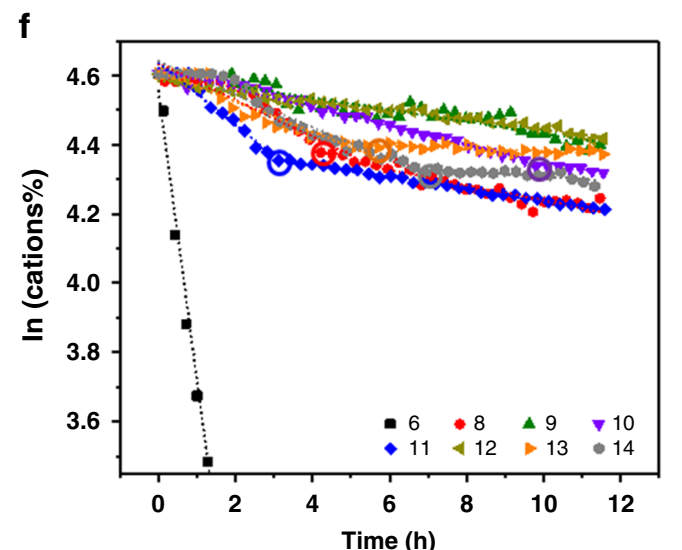

Fig. 2 Degradation of imidazolium. $\mathbf{a}$, b, c Selected regions of the ${ }^{1} \mathrm{H} N M R$ spectra of $\mathbf{9}(0.02 \mathrm{M})$ in $3 \mathrm{M} \mathrm{NaOD} / \mathrm{CD}_{3} \mathrm{OD} / \mathrm{D}_{2} \mathrm{O}\left(7: 3\right.$ wt. $\left.C D_{3} \mathrm{OD}: \mathrm{D}_{2} \mathrm{O}\right)$ after being heated at $80^{\circ} \mathrm{C}$ as a function of time. d, Compounds structure corresponding to plot in Fig. 2f. e, Degradation pathways of imidazolium cation. f Remaining percentage of model compounds $\mathbf{6}$ and 8-14 as a function of time at $\lambda=1$ and $0.5 \mathrm{M} \mathrm{OH}^{-}$at room temperature. Circled points represent break points, see text for details. NMR-determined stability data of novel compound 9-14 are provided in Supplementary Figs. 1-12 
a

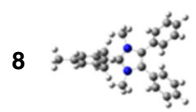
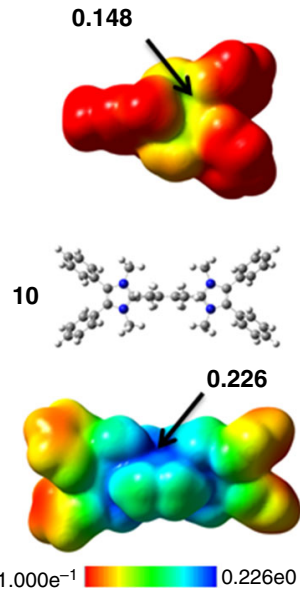

$1.000 \mathrm{e}^{-1} \mathbb{2} 0.226 \mathrm{e} 0$ b

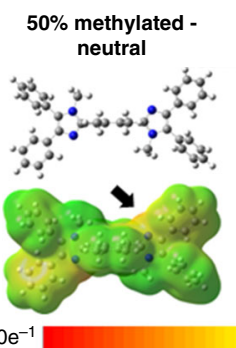

$-1.000 \mathrm{e}^{-1}$
C

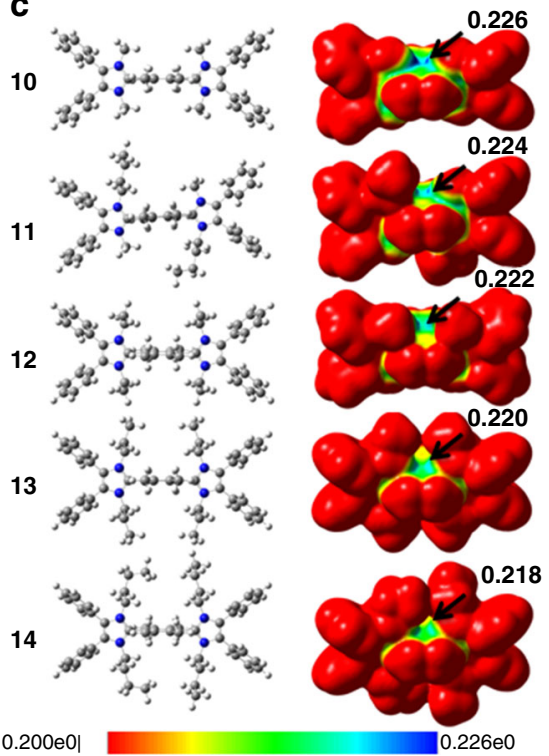

d

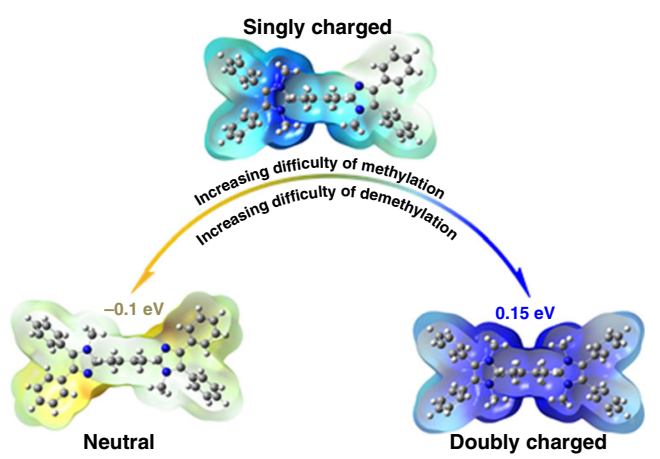

e

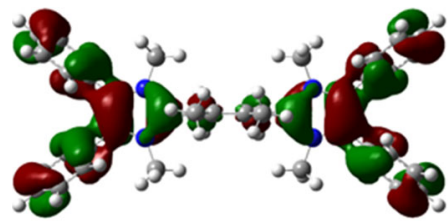

HOMO
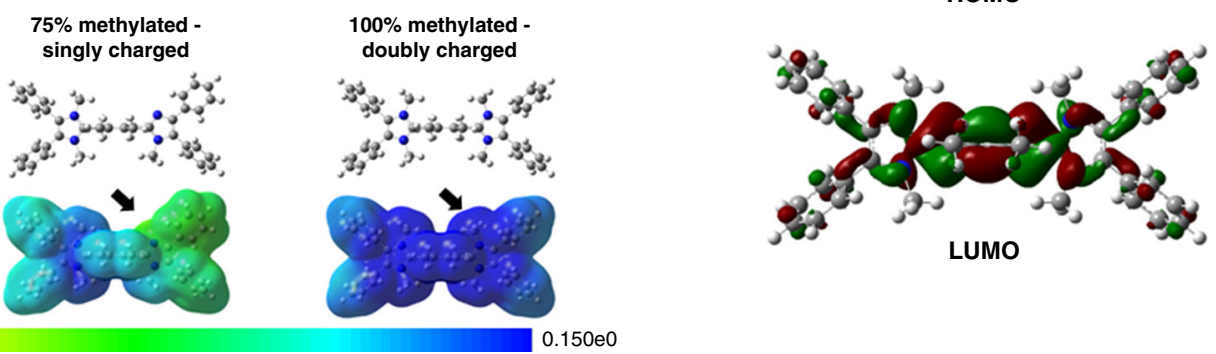

Fig. 3 DFT analyses of imidazoliums. a Electrostatic potentials (ESP) of $\mathbf{8}$ and $\mathbf{1 0}$ (potential bar 0.1 to $0.226 \mathrm{eV}$ ); b dimethylated (neutral), trimethylated (singly charged), and tetramethylated (doubly charged) imidazole (or imidazolium) (potential bar -0.1 to $0.15 \mathrm{eV}$ underneath); c ESP of 10-14 (potential bar $0.2-0.226 \mathrm{eV}$ ). $\mathbf{d}$ Methylated or demethylated scheme of compound 10. e HOMO and LUMO orbitals of 10

supported by ESP calculations where it can be shown that the positive charge of one imidazolium lowers the electron density and nucleophilicity of the nitrogen on the adjoining imidazole (Fig. 3b). Here, the neutral precursor of $\mathbf{1 0}(50 \%$ methylated) possesses a lower ESP than the non-methylated $\mathrm{N}$ - for the singly charged version of 10 ( $75 \%$ methylated), indicating that one positive charge on compound $\mathbf{1 0}$ renders the remaining nonmethylated $\mathrm{N}$ a weaker nucleophile for the final alkylation reaction (Fig. 3d). Furthermore, DFT calculations predict that upon dealkylation of one of the alkyl groups in $\mathbf{1 0}$, the remaining imidazolium is further stabilized. Despite activation toward mono-dealkylation of 10, caused by formation of the second cationic charge, compound $\mathbf{1 0}$ exhibits a remarkable half-life of $>2000 \mathrm{~h}$ under aggressive, caustic alkaline conditions. Attaching longer alkyl chains, with their stronger electron-donating effect on the imidazolium ring, reduces the DFT-calculated ESP values, as shown in Fig. 3c. Moreover, longer alkyl chains confer increased steric hindrance around the alkyl-N bond. Thus, 12-14 exhibit exceptional stabilities of $>10,000 \mathrm{~h}$ (Fig. 1) in $3 \mathrm{M} \mathrm{NaOD} /$ $\mathrm{D}_{2} \mathrm{O} / \mathrm{CD}_{3} \mathrm{OD}$. For completion, NMR-determined stability data of compounds 9-14 are shown in Supplementary Figs. 1-12.

Stability under $\lambda=1$ conditions. Given that the stability of several bis-imidazoliums in $3 \mathrm{M} \mathrm{NaOD} / \mathrm{D}_{2} \mathrm{O} / \mathrm{CD}_{3} \mathrm{OD}$ were indistinguishably high, harsher conditions were examined to probe their relative stability. Recently, Dekel et al. ${ }^{28-31}$ reported that very low hydration levels accelerate degradation of cationic groups in alkaline media, and that hydration levels of $\lambda<5$ increases the rate of degradation of cationic groups by up to several orders of magnitude. Model compounds 1-14 were therefore examined under minimal hydration, i.e., $\lambda=1$, using ultra-dry $\mathrm{KOH}(0.5 \mathrm{M}$ in dimethyl sulfoxide (DMSO)/crown ether) according to the procedure outlined in ref. ${ }^{32}$. The evolution of NMR spectra of the degradation of model compounds is shown in Supplementary Figs. 13-24 and the rate of degradation is plotted in Fig. $2 \mathrm{f}$ and tabulated in Supplementary Table 1. As anticipated, all compounds exhibited orders of magnitude lower stability under these hasher conditions. Interestingly, it was observed that Hoffmann degradation of the alkane side chains is the dominant decomposition pathway under these conditions, as opposed to dealkylation as was observed in $3 \mathrm{M} \mathrm{NaOD} / \mathrm{D}_{2} \mathrm{O} /$ $\mathrm{CD}_{3} \mathrm{OD}$. These results are consistent with the DFT calculations carried out for $\lambda=0$ condition ${ }^{25}$, which provides evidence that the preferential degradation pathway does not solely depend on the structure of cationic groups; hydration level also plays an important role. Under these ultra-low hydration levels, 1 and 3 exhibit the highest chemical stability with half-lives $>180$ and 600 $h$, respectively, due to the absence of $\beta$-hydrogens; nucleophilic attack by the hydroxide ion is dominant in this environment ${ }^{30,32}$. However, although the 1 and 3 are stable in the $\lambda=1$ condition, when they are attached to a polymer, they are not stable in the actual operation, such as fuel cell (FC) and water electrolysis, as the $\lambda$ level is generally higher in these devices. The trends of stability of the (benz)imidazoliums under these conditions are consistent in trend with their stability in $3 \mathrm{M} \mathrm{NaOD} / \mathrm{D}_{2} \mathrm{O} /$ $\mathrm{CD}_{3} \mathrm{OD}$, where compounds $\mathbf{6}, \mathbf{8}$, and $\mathbf{9}$ exhibit increasing stability. The least stable model compounds under low hydration 


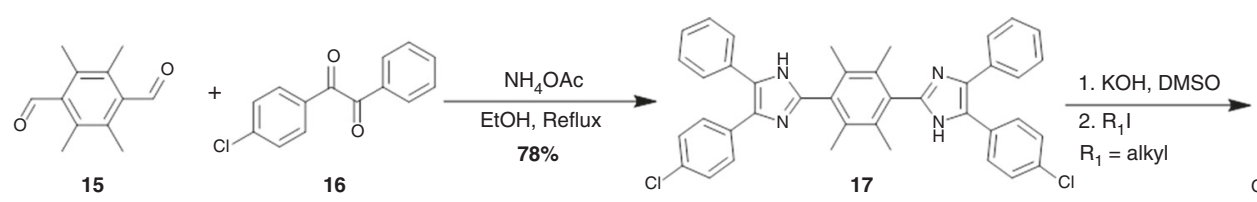

16

c

17

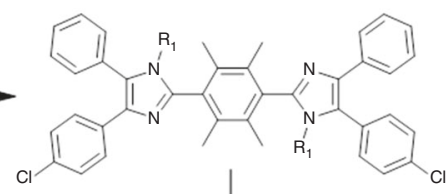

18, $R_{1}=$ methyl, $93 \%$ $19, R_{1}=$ ethyl, $91 \%$

$\mathrm{Ni}(\mathrm{COD})_{2}$, bipy $20, \mathrm{R}_{1}=$ propyl, $94 \%$ DMF, $80 \mathrm{C}$

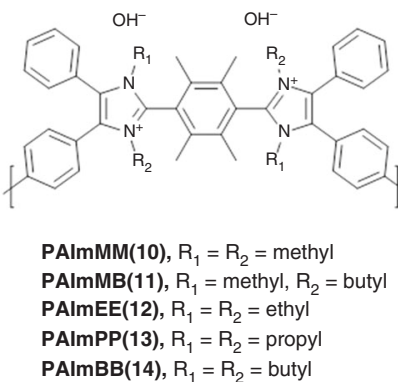

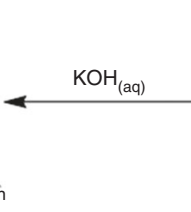
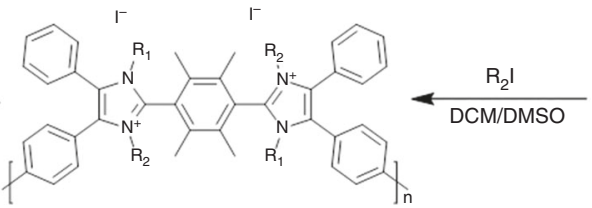

PAImMM(10), $R_{1}=R_{2}=$ methyl, $100 \%$ PAImMB(11), $R_{1}=$ methyl, $R_{2}=$ butyl, $100 \%$ PAImEE(12), $R_{1}=R_{2}=$ ethyl, $100 \%$ PAImPP(13), $R_{1}=R_{2}=$ propyl, $99 \%$ PAImBB(14), $R_{1}=R_{2}=$ butyl, $98 \%$ $21, R_{1}=$ butyl, $89 \%$

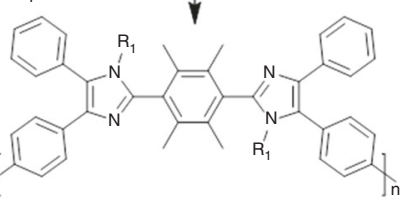

22, $\mathrm{R}_{1}=$ methyl, $95 \%$ 23, $R_{1}=$ ethyl, $98 \%$ $24, \mathrm{R}_{1}=$ propyl, $97 \%$ $25, R_{1}=$ butyl, $96 \%$

Fig. 4 Synthesis of poly(arylimidazoliums) PAImXY(\#). X and $Y$ represent alkyl chains and \# represents the analogous model compound illustrated in Fig. 1. Five polymers were synthesized: $P A I m M M(10), P A I m M B(11), P A I m E E(12), P A I m P P(13)$, and PAImBB(14), possessing the same architecture as compounds 10-14, where $\mathrm{M}=$ methyl, $\mathrm{E}=$ ethyl, $\mathrm{P}=$ propyl, and $\mathrm{B}=$ butyl

conditions were $\mathbf{2}, \mathbf{4}, \mathbf{5}$, and 7 , which decomposed immediately to the extent that degradation plots were unobtainable. Bisimidazolium compounds 10, 11, 13, and 14 exhibited a twostage rate of degradation, which is also consistent with the calculations illustrated in Fig. 3b-d, which indicate that after the loss of one $\mathrm{N}$-alkyl group (and hence loss of the first cationic charge), the remaining cationic group is less susceptible to degradation. The calculated highest occupied molecular orbital and lowest unoccupied molecular orbital orbit of $\mathbf{1 0}$ provide additional evidence that the positive charge is distributed over the N1/C2/N3 atoms of the imidazole ring and also explains why deuterium exchange may occur at protons associated on the tetramethylphenyl group (Fig. 2a).

Poly(arylimidazoliums). As compounds 12-14 demonstrated exceptional chemical stability in both $3 \mathrm{M} \mathrm{NaOD} / \mathrm{D}_{2} \mathrm{O} / \mathrm{CD}_{3} \mathrm{OD}$ $(\lambda=4.8)$ and $0.5 \mathrm{M} \mathrm{KOH} / \mathrm{DMSO} /$ crown ether $(\lambda=1)$, analogous polymers with the same molecular architecture were designed and synthesized. Novel, sterically protected poly(arylimidazoliums) were prepared by Yamamoto-coupling homo-polymerization of dichloro-imidazole monomers as shown in Fig. 4. This synthetic route is substantially different to that previously reported for a poly(arylimidazoliums), which was based on a bis-diketone/dialdehyde/ammonium polycondensation ${ }^{24}$. The newly devised route is an important advancement, as it mitigates issues of solubility during polymerization that limit the molecular weight of the poly (arylimidazoliums).

Biaryl couplings in a polymer generally lead to low-molecularweight polymer, because highly rigid aromatic backbones reduce their solubility. However, the synthetic strategy adopted allowed preparation of an intermediary polymer, in its semi-alkylated form, which afforded much higher solubility, higher highmolecular-weight poly(arylimidazoles) $(\mathrm{Mw}=140 \mathrm{kDa}$, Polydispersity Index $=1.70$ ), as shown in Supplementary Fig. 25 . Nalkylation of the polymers was achieved by reacting the polymer with different alkylating reagents in dichloromethane/DMSO at $80^{\circ} \mathrm{C}$ in a pressure reactor for 3 days, to produce various poly (arylimidazoliums) in their iodide form. Transparent, colorless, flexible, and tough membranes were obtained after casting and washing with $1 \mathrm{M} \mathrm{KOH}$ (Supplementary Fig. 26, Table 1). Membranes were converted to the chloride form and characterized. As shown in Table 1, PAImMM(10) $\mathrm{Cl}^{-}$exhibits an anion conductivity of $33 \mathrm{mS} \mathrm{cm}^{-1}$ for a hydration level of 9 . The swelling of PAImMM(10) $\mathrm{Cl}^{-}$in water is $45 \mathrm{wt} \%$, which is low given the membrane's high IEC, $2.86 \mathrm{mmol} \mathrm{g}^{-1}$. Polymers prepared with longer alkyl side chains correspondingly possess lower IEC 33,34 . The swelling of PAImEE(12), PAImPP(13), and PAImBB(14) decreases from $26.1 \%$ to $20.3 \%$, to $14.0 \%$, with calculated $\lambda$-values of 6,5 , and 3 , respectively. Compared with PAImEE(12), the unsymmetrically alkylated polymer PAImMB (11) has a higher water uptake and hydration level, although it possesses a lower IEC and swelling ratio than PAImEE(12). Maximum conductivities of 82 and $12 \mathrm{mS} \mathrm{cm}^{-1}$ were observed at $80{ }^{\circ} \mathrm{C}$ under $95 \%$ relative humidity $(\mathrm{RH})$ for PAImMM(10) and $\operatorname{PAImBB}(14)$ (Fig. 5a), respectively. The large difference in conductivity is due to the $0.5 \mathrm{mmol} \mathrm{g}^{-1}$ difference in IEC and subsequent decrease in water content. A clear relationship between conductivity and IEC can be observed from Fig. 5b.

Chemical stability to caustic solutions was examined by calculating the percentage of the imidazolium remaining in the polymer after immersion in $10 \mathrm{M} \mathrm{KOH}$ at $80{ }^{\circ} \mathrm{C}$ as a function of time (Supplementary Figs. 27-31). Imidazolium units of $66.0 \%$, 93.6\%, 93.9\%, and $97.7 \%$ in $\operatorname{PAImMM(10),~PAImEE(12),~}$ $\operatorname{PAImPP}(13)$, and $\operatorname{PAImBB}(14)$, respectively, remained intact after $240 \mathrm{~h}$. The stability of PAImXY(\#) to highly caustic solutions increases with the $\mathrm{N}$-alkyl length, which is consistent with the alkaline stability of the model compounds The two-stage degradation of PAImMM(10) observed in low hydration conditions (Fig. 5c, black) and the observation of the inflection point around $20 \%$ degradation is also consistent with degradation rate of the model compounds in alkaline/low water content media (Fig. 2f, purple). However, according to the ${ }^{1} \mathrm{H}$ NMR analysis, the degradation of the membranes occurs via both dealkylation (major) and ring-opening (minor) pathways, which is different from that of the model compound where only dealkylation was observed. The detection of ring-opening degradation, albeit relatively minor (dealkylation: ring-opening is 4:1), shows up here not only because of the lower $\lambda$-value $\left(4.3\right.$ for $10 \mathrm{M} \mathrm{KOH}_{\mathrm{aq}}$ vs. 4.8 for $3 \mathrm{M} \mathrm{NaOD} / \mathrm{D}_{2} \mathrm{O} / \mathrm{CD}_{3} \mathrm{OD}$ ) but possibly due to torsional stress within the polymer, which may reduce the dihedral angle between tetramethylphenyl and the imidazolium ring leading to reduced steric hindrance around the $\mathrm{C} 2$-imidazolium.

On the basis of their relatively high anion conductivity and high stability in caustic solutions, $\operatorname{PAImEE(12)}$ and $\operatorname{PAImBB}(14)$ 
Table 1 Properties of PAImXY(\#) membranes

\begin{tabular}{|c|c|c|c|c|c|c|c|c|}
\hline & $\begin{array}{l}\text { Water } \\
\text { uptake (wt \%) }\end{array}$ & Swelling (wt\%) & $\begin{array}{l}\mathrm{IEC}_{\mathrm{CI}}{ }^{\mathrm{a}}(\mathrm{mmol} \\
\left.\mathrm{g}^{-1}\right)\end{array}$ & $\lambda^{\mathbf{b}}$ & $\sigma^{c}\left(\mathrm{mS} \mathrm{cm}^{-1}\right)$ & $\mathrm{TS}^{\mathrm{d}}(\mathrm{MPa})$ & $E @ B^{e}(\%)$ & Modulus $^{f}(\mathrm{MPa})$ \\
\hline $\begin{array}{l}\text { PAImMM } \\
\text { (10) }\end{array}$ & $48.2 \pm 1.3$ & $45.0 \pm 2.3$ & 2.86 & 9 & $32.7 \pm 2.4$ & $75.0 \pm 3.9$ & $17.4 \pm 2.7$ & $1549 \pm 148$ \\
\hline PAImEE(12) & $28.1 \pm 1.6$ & $26.1 \pm 4.0$ & 2.65 & 6 & $21.3 \pm 1.6$ & $64.0 \pm 11.6$ & $28.7 \pm 8.0$ & $1075 \pm 212$ \\
\hline PAImPP(13) & $22.3 \pm 1.3$ & $20.3 \pm 2.0$ & 2.46 & 5 & $14.8 \pm 1.2$ & $57.2 \pm 2.0$ & $19.5 \pm 1.2$ & $1292 \pm 46$ \\
\hline PAImBB(14) & $12.2 \pm 2.0$ & $14.0 \pm 1.2$ & 2.30 & 3 & $8.5 \pm 0.7$ & $65.2 \pm 5.3$ & $20.4 \pm 1.8$ & $1095 \pm 54$ \\
\hline
\end{tabular}

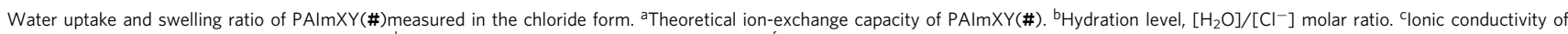
PAImXY(\#) in chloride form at $22^{\circ} \mathrm{C}$ in water. ${ }^{\mathrm{d} T S}$ tensile strength. ${ }^{\mathrm{E}} @ \mathrm{~B}$ elongation at break. ${ }^{\mathrm{f}}$ Young's modulus
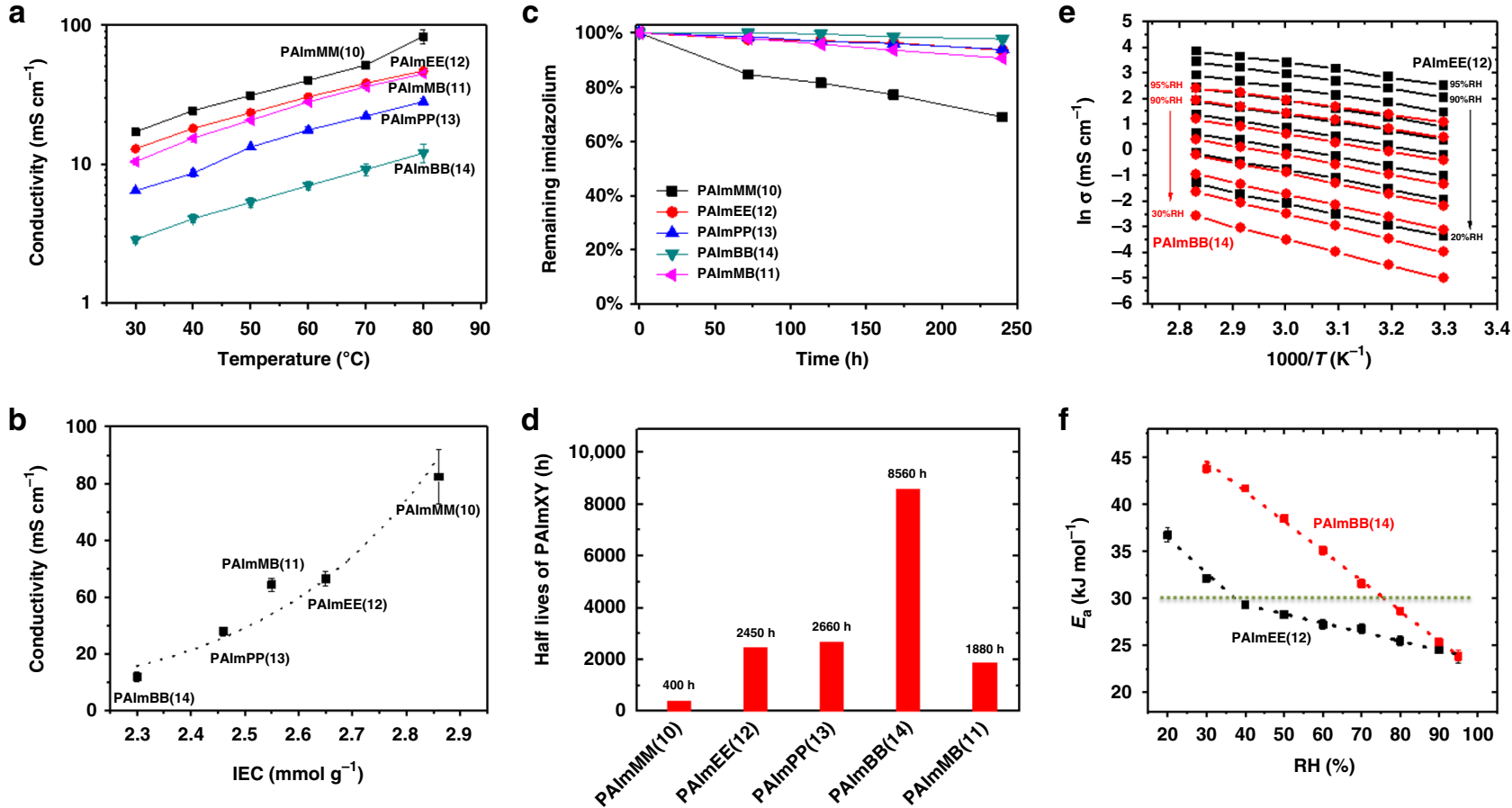

Fig. 5 Properties of PAImXY(\#). a lonic conductivity of PAImXY(\#) $\left(\mathrm{Cl}^{-}\right)$. Temperature-dependent conductivity under $95 \%$ RH. b lonic conductivity at $80^{\circ} \mathrm{C}, 95 \% \mathrm{RH}$ vs. IEC of PAImXY(\#). c Stability of PAImXY(\#) to caustic solution after immersion in $10 \mathrm{M} \mathrm{KOH}$ at $80^{\circ} \mathrm{C}$ for $240 \mathrm{~h} . \mathbf{d}$ Calculated half-life. e Arrhenius plots of ion conductivity of PAImEE(12) (black) and PAImBB(14) (red) in chloride form at various temperature and RH in air. $\mathbf{f}$ The corresponding calculated activation energy at a given $\mathrm{RH}$

were chosen for further study. The anion conductivity of PAImEE (12) $\mathrm{Cl}^{-}$and $\mathrm{PAImBB}(14) \mathrm{Cl}^{-}$, measured at various temperatures and humidities, follows an Arrhenius-type behavior shown in Fig. 5e. Both PAImEE(12) and $\operatorname{PAImBB}(\mathbf{1 4})$ possess a similar $E_{\mathrm{a}}$ of $24 \mathrm{~kJ} \mathrm{~mol}^{-1}$ at $95 \% \mathrm{RH}$ (Fig. $5 \mathrm{f}$ ). The $E_{\mathrm{a}}$ of $\operatorname{PAImBB}(14)$ is always higher than that of PAImEE(12) below $95 \% \mathrm{RH}$, because there is a difference in the dependence of $E_{\mathrm{a}}$ with humidity. Whereas $E_{\mathrm{a}}$ for $\operatorname{PAImBB}(\mathbf{1 4})$ increases linearly as the humidity is decreased over the range measured, $E_{\mathrm{a}}$ for PAImEE(12) increases slowly with decreasing $\mathrm{RH}$ until $\mathrm{RH}=40 \%$, at which point $E_{\mathrm{a}}$ increases more rapidly. This suggests that at $\mathrm{RH}<40 \%$, a change in hydration level causes a significant change in the activation of chloride ion transport for PAImEE(12). This is consistent with the lower water sorption properties of $\operatorname{PAImBB}(14)$ compared with PAImEE(12), with the fact that a decreasing quantity of imbibed water will ultimately lead to poorly connected hydrophilic regions and a larger energy barrier for ion transport.

Morphology. X-ray scattering was employed to determine the morphology of PAImXY(\#) membranes and explore changes in morphology induced by changing the $\mathrm{N}$-alkyl group. X-ray scattering of the iodide form of PAImMM(10) under vacuum (Fig. 6a, yellow) yields a complex scattering pattern: four distinct peaks are located at $\sim 4,8,16$, and $20 \mathrm{~nm}^{-1}$. Only the $16 \mathrm{~nm}^{-1}$ peak changes position significantly for polymer analogs bearing longer $\mathrm{N}$-alkyl groups, although the 4 and $20 \mathrm{~nm}^{-1}$ peaks weaken in intensity. Only the 8 and $16 \mathrm{~nm}^{-1}$ peaks are clearly visible in the scattering profile for $\operatorname{PAImBB}(14)$ (Fig. 6a, b, red). The $4 \mathrm{~nm}$ -1 and $8 \mathrm{~nm}^{-1}$ peaks correspond to Bragg lengths of $\sim 1.6$ and $0.8 \mathrm{~nm}$. As DFT results reveal that the monomer length is $1.6 \mathrm{~nm}$, we interpret these peaks as being the monomer-monomer and anion-anion spacings along the polymer backbone. The $16 \mathrm{~nm}^{-1}$ peak corresponds to a Bragg length of $\sim 0.4 \mathrm{~nm}$ and is assigned to the distance between the anion and the cationic imidazolium unit. The $16 \mathrm{~nm}^{-1}$ peaks shift to higher scattering wavevector (Fig. 6b) as the $\mathrm{N}$-alkyl group is lengthened from methyl to butyl, which implies the distance between anion and imidazolium is decreasing. This is consistent with X-Ray diffraction (XRD) single-crystal analysis of the model compounds 10-14, which shows that anion resides closer to the imidazolium ring as the $\mathrm{N}$-alkyl group 
a

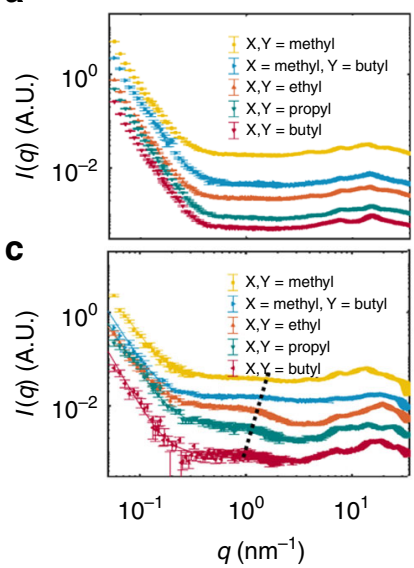

b

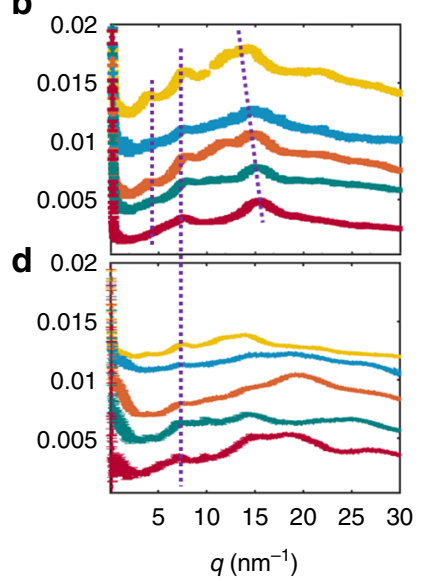

e

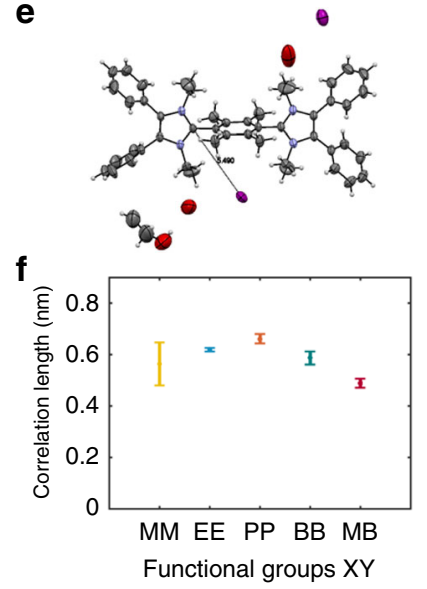

Fig. 6 X-ray scattering profiles of PAImXY(\#) and X-ray crystal structure of $\mathbf{1 2}$. X-ray scattering profiles of PAImXY(\#)(I-) in vacuo (a, b) and hydrated (c, d). Figures in the left hand column $(\mathbf{a}, \mathbf{c})$ are plotted on a log-log scale to show overall structure. Figures in the middle column (b, d) are plotted lin-lin to focus on the wide-angle scattering (smaller structure). The curves are vertically offset for clarity. e X-ray crystal structure of model compound $\mathbf{1 2}$ in its iodide form (ellipsoid set at 50\% probability) with distance of iodide to C2 represented by a line. $\mathbf{f}$ The size of the correlated regions observed in the hydrated samples with different side chains obtained by fitting Equation 6 to the SAXS data

increases in length and may be caged within longer $\mathrm{N}$-alkyl groups. Supplementary Figs. 32-36 show single-crystal unit cells with anion-imidazolium distances of 8.95, 5.14, 5.49, 5.28, $4.62 \AA$, respectively, for $10,11,12,13$, and 14 , respectively. The crystal structure of compound $\mathbf{1 2}$ is shown in Fig. 6e as an example here. Although the precise origin of the $20 \mathrm{~nm}^{-1}$ is not known, the corresponding length scale is inter-atomic. X-ray scattering plots of hydrated materials are shown in Fig. 6c, d. A scattering knee is apparent at $\sim 1 \mathrm{~nm}^{-1}$ for all samples, although more visible in PAImEE(12), PAImPP(13), and PAImBB(14). This scattering is attributed to correlated water-rich hydrophilic regions. The fact that the peak is more prominent in the materials with longer side chains suggests that the water-rich regions are more distinct in these materials. Results of fitting Eq. 6 to the scattering data are shown in Fig. 6f. The correlation length of the water-rich regions increases with $\mathrm{N}$-alkyl length in the materials. The material with mixed $\mathrm{N}$-alkyl units, $\mathrm{PAImMB}(11)$ shows a shorter correlation length, although the knee was extremely weak in this data. Transmission electron microscopic analyses also indicate that phase segregation becomes more distinct as alkyl chain attached to the N-groups is lengthened (Supplementary Fig. 37). Despite increased phase segregation being synonymous with enhanced water-rich regions and enhanced ionic pathways for promoting ion conductivity ${ }^{35-40}$, this is not the case in $\operatorname{PAImXY(\# ),~because~}$ in this instance increasing the $\mathrm{N}$-alkyl length not only cages the anions but also reduces the IEC and hence water content, resulting in poorly connected hydrophilic regions, which explains the lower $E_{\mathrm{a}}$ of $\mathrm{PAImEE}(\mathbf{1 2})$ compared with $\operatorname{PAImBB}(\mathbf{1 4})$ (Fig. 5f).

Analyses in FCs and water electrolyzers. As a proof-of-principle of the applicability of these polymers in electrochemical devices, PAImBB(14) membrane was incorporated into an AEMFC, and $P A \operatorname{ImBB}(\mathbf{1 4})$ and PAImEE(12) were each integrated into an AAEM electrolyzer (AEM EL). Electrodes were prepared using solid powder anion-conducting ionomers and catalysts, as reported in details elsewhere ${ }^{41}$. Immediately after equilibration at $60^{\circ} \mathrm{C}$, the cell was polarized without back pressure and a peak power density of $170 \mathrm{~mW} \mathrm{~cm}{ }^{-2}$ was achieved. After increasing cell temperature to $70^{\circ} \mathrm{C}$, peak power density of $250 \mathrm{~mW} \mathrm{~cm}-2$ was achieved, as shown in Fig. 7a. It must be remarked that AEMFC tests cannot typically be operated at temperatures > $60^{\circ} \mathrm{C}$, indicating the enhanced thermal stability of the membranes studied in this work. $\operatorname{PAImEE}(\mathbf{1 2})$ and $\operatorname{PAImBB}(\mathbf{1 4})$ membranes were incorporated into a water electrolysis cell operated in $6 \mathrm{M} \mathrm{KOH}$ liquid electrolyte between 60,70 , and $80^{\circ} \mathrm{C}$. A commercial FAA-3 (Fumatech) AEM operated in $1 \mathrm{M}$ $\mathrm{KOH}$ was used for comparison. As shown in Fig. 7b, both PAI$\mathrm{mEE}(\mathbf{1 2})$ and $\operatorname{PAImBB}(\mathbf{1 4})$ membranes were functional as an ionic separator in the water EL. At a current density of $400 \mathrm{~mA}$ $\mathrm{cm}^{-2}$, the voltage remained below $2.5 \mathrm{~V}$. Higher performance can be achieved by increasing the operating temperature. Figure $7 \mathrm{c}$ shows a $0.2 \mathrm{~V}$ potential drop from 60 to $80^{\circ} \mathrm{C}$ for PAImEE(12). Stable operation of membranes at temperatures $>60^{\circ} \mathrm{C}$ is atypical and again demonstrates enhanced stability of the poly(bis-imidazoliums). A PAImEE(12), $25 \mu \mathrm{m}$-thick membrane cell was operated at $60^{\circ} \mathrm{C}$ with $6 \mathrm{M} \mathrm{KOH}$ under $400 \mathrm{~mA} \mathrm{~cm}^{-2}$ for $48 \mathrm{~h}$ (Fig. 7d). The break in the cell represents a reconditioning protocol, as trace impurities have been shown to strongly affect the rate of hydrogen evolution $22,42,43$; after reconditioning, the potential was significantly lowered, followed by a gradual increase due to commencement of poisoning of the electrodes. Comparatively, commercial FAA run using the same setup under much milder caustic conditions (1 $\mathrm{M} \mathrm{KOH})$ and much lower current density $\left(20 \mathrm{~mA} \mathrm{~cm}^{-2}\right)$ failed after $9.5 \mathrm{~h}$. The PAImEE(12) cell was eventually shut down, not because of membrane degradation but due to increased resistance of the uncoated titanium bipolar plate, which had undergone severe corrosion under contact with hot caustic solution. Despite this, the potential remained less than $2.6 \mathrm{~V}$ after $48 \mathrm{~h}$, showing promising chemical durability of the PAImEE(12) membranes.

\section{Discussion}

Novel polymers have been designed and synthesized based on a molecular design using DFT calculations, investigation of model compounds via crystal structure analysis, and state-of-the-art degradation analysis under low water content conditions. These bis-imidazolium polymers and membranes offer a balanced alkaline stability and high IEC that provides exceptional chemical stability and hydroxide conductivity with low water content. Moreover, a novel versatile synthetic route is presented, which facilitates further investigations of numerous derivations and compositions of these poly(arylimidazolium) hydroxide. Future emphasis should be placed on improving mechanical properties 
a

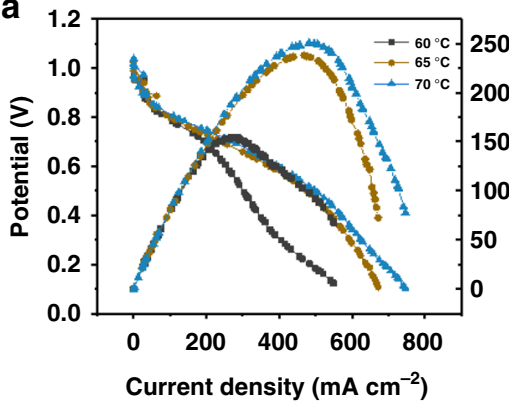

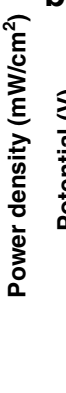

b 2

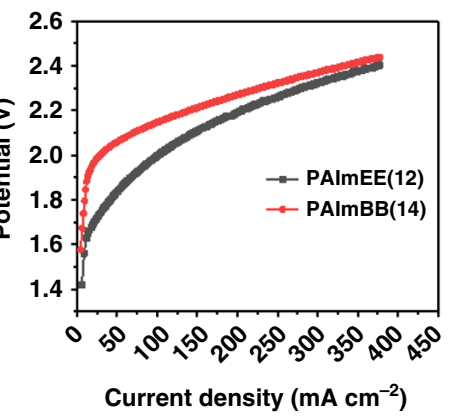

C

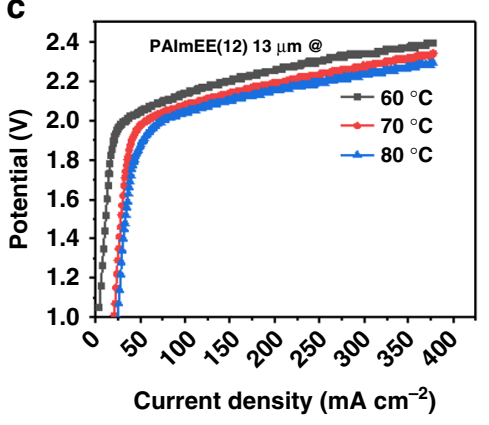

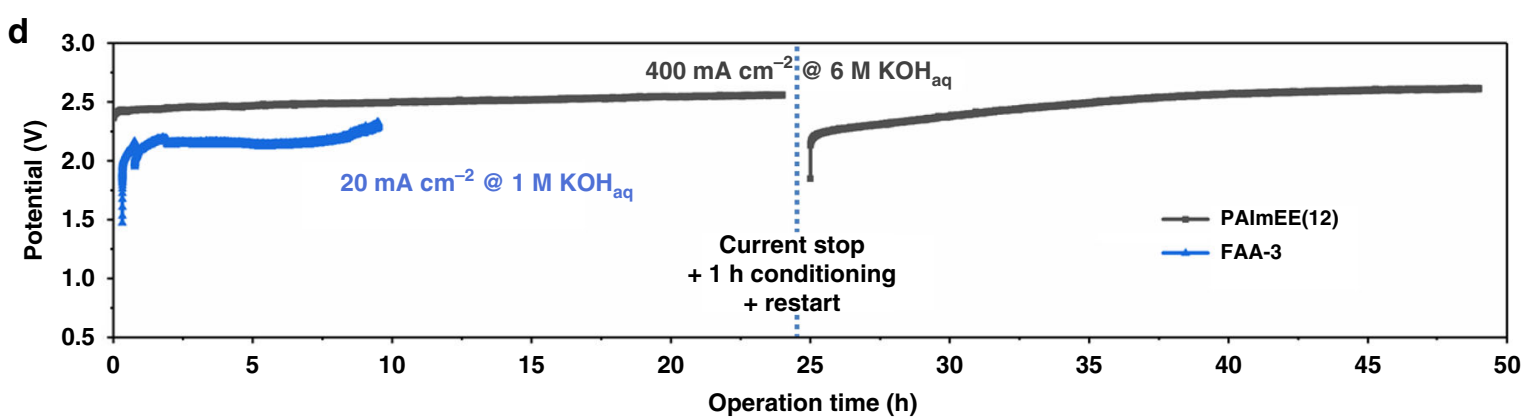

Fig. 7 I-V curves for fuel cells and water electrolyzers. a Polarization curves of PAlmBB(14) AEMFC with $0.5 \mathrm{mg}$ PtRu per $\mathrm{cm}^{2}$ (anode) and $0.5 \mathrm{mg}$ Pt per $\mathrm{cm}^{2}$ (cathode), and $20 \mu \mathrm{m}$ membrane thickness. Conditions were 60,65 , and $70^{\circ} \mathrm{C}$, respectively. Here, $1 \mathrm{~mL} \mathrm{~min}^{-1}$, zero back pressure. b Polarization curves of PAImEE(12) $\left[25 \mu \mathrm{m}\right.$ thick] and PAImBB(14) $\left[20 \mu \mathrm{m}\right.$ thick] AEM electrolyzer at $60^{\circ} \mathrm{C}$. c Polarization curves of PAImEE(12) [13 $\mu \mathrm{m}$ thick] AEM electrolyzer at 60,70 and $80^{\circ} \mathrm{C}$ in $6 \mathrm{M} \mathrm{KOH}$. d PAImEE(12), $25 \mu \mathrm{m}$, maintained at $400 \mathrm{~mA} \mathrm{~cm}^{-2}$, and FAA-3, $25 \mu \mathrm{m}$, at $20 \mathrm{~mA} \mathrm{~cm}^{-2}$ at $60^{\circ} \mathrm{C}$. The difference in voltage between FAA-3 and PAImEE(12) in c can be attributed to the different current densities at which the cell was operated

\section{Table 2 Chemical shift range used in degradation calculations}

\begin{tabular}{llll}
$\begin{array}{l}\text { Model } \\
\text { compounds }\end{array}$ & $\begin{array}{l}\text { Chemical shift } \\
\text { range for } \boldsymbol{x}_{\boldsymbol{t}}\end{array}$ & $\begin{array}{l}\text { Chemical shift } \\
\text { range for } \boldsymbol{y}_{\boldsymbol{t}}\end{array}$ & $\begin{array}{l}\text { Chemical shift } \\
\text { range for } \boldsymbol{z}_{\boldsymbol{t}}\end{array}$ \\
\hline $\mathbf{1 0}$ & $7.75-7.63$ p.p.m. & $7.63-7.42$ p.p.m. & $7.75-7.03$ p.p.m. \\
$\mathbf{1 1}$ & $7.64-7.46$ p.p.m. & $7.46-7.36$ p.p.m. & $7.24-7.11$ p.p.m. \\
$\mathbf{1 2}$ & $7.65-7.44$ p.p.m. & $7.44-7.32$ p.p.m. & $7.22-7.14$ p.p.m. \\
$\mathbf{1 3}$ & $7.65-7.42$ p.p.m. & $7.42-7.33$ p.p.m. & $7.24-7.13$ p.p.m. \\
$\mathbf{1 4}$ & 7.66-7.42 p.p.m. & $7.42-7.37$ p.p.m. & 7.32-7.24 p.p.m. \\
\hline
\end{tabular}

and polymer engineering, such as reinforcement, in order to facilitate their integration in electrochemical energy conversion devices.

\section{Methods}

Solution degradation test in $\mathbf{3} \mathbf{M} \mathbf{N a O D} / \mathbf{D}_{\mathbf{2}} \mathbf{O} / \mathrm{CD}_{\mathbf{3}} \mathrm{OD}$. The stability of model compounds were evaluated using a degradation test decribed in the literature ${ }^{21,24}$. A solution of the model compound $(0.02 \mathrm{M})$ was prepared by dissolving the compound in its iodide form in $3 \mathrm{M} \mathrm{NaOD}$ with $\mathrm{CD}_{3} \mathrm{OD} / \mathrm{D}_{2} \mathrm{O}\left(7: 3 \mathrm{CD}_{3} \mathrm{OD}: \mathrm{D}_{2} \mathrm{O}\right)$. The mixture was heated to $80^{\circ} \mathrm{C}$ in a closed polytetrafluoroethylene vial for up to $240 \mathrm{~h}$. At specific times, samples were extracted for ${ }^{1} \mathrm{H}$ NMR spectroscopic analysis. The degradation of compounds 10-14 was quantified using Equation 1 and chemical shift range shown in Table 2:

$$
\text { Relative imidazolium remaining }(\%)=100\left(\frac{\frac{x_{t}}{x_{t}+y_{t}+z_{t}}}{x_{0}+y_{0}+z_{0}}\right)
$$

where $x_{t}$ is the integration value for the aromatic peak region, and $y_{t}$ and $z_{t}$ is the degradation product peak $\left(x_{0}, y_{0}\right.$, and $z_{0}$ are $x_{t}, y_{t}$, and $z_{t}$ at time $0 \mathrm{~h}$, respectively).

Solution degradation test in KOH/DMSO-d6. Preparation of water-free hydroxide solution. In a three-neck flask, 18-crown-6 (CE) (Sigma-Aldrich) was heated to $60^{\circ} \mathrm{C}$ under argon environment. Potassium metal (Merck) was added to the flask to get a blue solution. A precise amount of mili-Q water was injected to the solution, which changed its color to brown, to produce ultra-dry potassium hydroxide, $\left(\mathrm{CE}-\mathrm{K}^{+}\right) \mathrm{OH}^{-}$. The mixture was then cooled to room temperature and stored in a glove box under a dry inert atmosphere.
All stability tests were carried out with a hydration level of $\lambda=1$ (1 water molecule per $\left.\mathrm{OH}^{-}\right)$. For each test, two solutions were prepared in a glove box: (1) $0.035 \mathrm{mmol}$ of QA salt was dissolved in $91 \mu \mathrm{L}$ DMSO-d6; (2) $0.5 \mathrm{mmol} \mathrm{OH}^{-}$from the $\left(\mathrm{CE}-\mathrm{K}^{+}\right) \mathrm{OH}^{-}$mixture was dissolved in $500 \mu \mathrm{L}$ DMSO- $d 6$. Then, $1.5 \mu \mathrm{L}$ of internal standard (mesitylene) and $9 \mu \mathrm{L}$ of mili-Q water were injected to the NMR tube just before the measurement. The hydroxide concentration was measured by titration and confirmed to be $0.5 \mathrm{M}$.

Casting procedure. The PAImXY(\#) polymer in iodide form was dissolved in $3 \mathrm{~mL}$ of hot DMSO, filtered onto a flat casting table, and allowed to slowly dry at $86^{\circ} \mathrm{C}$ for at least $4 \mathrm{~h}$ in air. The film was peeled off the glass as a transparent brown film and then washed with $2 \mathrm{M} \mathrm{KOH}$ three times (alternatively changed the solution per day) followed by $2 \mathrm{M} \mathrm{HCl}$ and $1 \mathrm{M} \mathrm{NaCl}$ to get a clean transparent chloride form membrane. The films produced by this method were transparent and were $\sim 10 \mu \mathrm{m}$ thick.

Mechanical strength. The membranes were die-cut to a barbell shape using a standard ASTM D638-4 cutter. The mechanical properties of the membranes were measured under ambient conditions on a single column system (Instron 3344 Series) using a crosshead speed of $5 \mathrm{~mm} \mathrm{~min}^{-1}$. The determined tensile strength, Young's moduli, and elongation at break were averaged over four samples. The error reported is the SD of four measurements.

Ionic conductivity. Membrane pieces of in their stable chloride form were used for the conductivity measurements. The ionic resistance was measured in the in-plane direction using a two-point probe by electrochemical impedance spectroscopy. Specifically, an AC potential was applied over a frequency range of $100-10^{7} \mathrm{~Hz}$ with a Solartron SI 1260 impedance/gain-phase analyzer at room temperature and in water. For conductivity measurement at various temperature and $\mathrm{RH}$, all membranes were equilibrated $40 \mathrm{~min}$ for every $10^{\circ}$ rise in temperature $2 \mathrm{~h}$ for every $10 \%$ increase in RH. The membrane charge transfer resistance $(R)$ determined from a best fit of a standard Randles circuit to the measured Nyquist plot was used to calculate the ionic conductivity $(\sigma)$ with Equation 2:

$$
\sigma=\frac{l}{A R}
$$

where $l$ is the distance between the two electrodes and $A$ is the cross-sectional area of the membrane.

Theoritical ion-exchange capacity. The IEC of PAImXY(\#) was calculated from the number of ion pairs per repeat unit of the polymer per molecular weight of that 
repeat unit.

$$
\text { IEC }=\frac{\text { Number of ionic pairs per repeat unit }}{\text { Molecular weight of repeat unit }}
$$

Water content $\lambda$. The membrane was exchanged to the chloride form as described in the previous section on ionic conductivity. The hydrated membrane was removed from deionized waterdabbed with Kimwipes ${ }^{\mathrm{TM}}$, to remove any excess water on the surface, and weighed immediately $\left(W_{\mathrm{w}}\right)$. The "wet" membrane was then dried under vacuum at $80^{\circ} \mathrm{C}$ to obtain a constant dry weight $\left(W_{\mathrm{d}}\right)$. Water uptake $\left(W_{\mathrm{u}}\right)$ for three samples was calculated using Equation 4 and the SD of measurements is reported.

$$
W_{\mathrm{u}}=\frac{W_{\mathrm{w}}-W_{\mathrm{d}}}{W_{\mathrm{d}}}
$$

Lambda, i.e., the number of water molecules per mobile anion, was calculated using the following equation.

$$
\lambda=10 \frac{W_{\mathrm{u}}}{\mathrm{Mw}_{\text {water }} \times \mathrm{IEC}}
$$

Transmission electron microscopy. The morphologies of the membranes in their as-cast iodide form were observed using a transmission electron microscope (JEOL JEM-3010 h). The dry membrane was embedded into epoxy resin cut into $100 \mathrm{~nm}$ thick sections using a diamond knife ultramicrotome.

Membrane degradation test. $\mathrm{PAImXY}(\#)$ membranes were converted to their chloride form by soaking in $1 \mathrm{M} \mathrm{NaCl}_{\mathrm{aq}}$ for $48 \mathrm{~h}$ (exchanging the solution with fresh $1 \mathrm{M} \mathrm{NaCl}$ after $12 \mathrm{~h}$ ) and then washed with deionized water over $48 \mathrm{~h}$ with multiple exchanges of water. The membranes were immersed $10 \mathrm{M} \mathrm{NaOH}_{\mathrm{aq}}$ in closed FEP containers inside an $80^{\circ} \mathrm{C}$ oven for up to $240 \mathrm{~h}$. The membranes were removed and converted back to their chloride form by repeating the $1 \mathrm{M} \mathrm{NaCl}_{\mathrm{aq}}$ soak $(48 \mathrm{~h})$ and water wash $(48 \mathrm{~h})$. After drying, the membranes were dissolved in DMSO- $d 6$ for ${ }^{1} \mathrm{H}$ NMR spectroscopic analysis.

Small angle X-ray scattering. X-ray scattering measurements were performed using a SAXSLab Ganesha 300XL equipped with a mobile PILATUS3 R $300 \mathrm{~K}$ photon counting detector. The instrument utilizes a copper anode source, operating at $50 \mathrm{kV}$ and $0.6 \mathrm{~mA}$, which produces radiation with a wavelength of $1.54 \AA$. Four different configurations were utilized to provide a usable $q$-range of $\sim 0.05$ to $3 \mathrm{~nm}^{-1}$. Measurements were performed in vacuum and after hydration in deionized water. Samples measured in vacuum were allowed to equilibrate within the evacuated instrument chamber for $1 \mathrm{~h}$. Hydrated samples were immersed in deionized water for $1 \mathrm{~h}$, patted dry with tissue, and measured in sealed cells. Two model functions were fit to the data. The Correlation Length Model was fit to the mid- $q$ feature visible in the wet data to extract a characteristic length scale from the data. This function is given by

$$
I(q)=\frac{A}{q^{n}}+\frac{C}{1+(q \xi)^{m}}+B
$$

where $A$ and $C$ are scale factors, $\xi$ is the correlation length, $n$ is the low- $q$ Porod exponent, $m$ is the mid- $q$ Porod exponent, and $B$ is the $q$-independent background. As it tended to become extremely large in measurements where the feature was weak, $m$ was fixed at 4 , the best-fit value in measurements where the feature was very clear.

A series of pseudo-Voigt functions, which provide a flexible peak shape [ref], was fit to the measurements of PAImBB in vacuum, in order to estimate the $q$ independent scattering and produce a background-subtracted plot. This fitting function is given by

$$
I(q)=\frac{A}{q^{n}}+\sum_{i}\left\{\begin{array}{c}
S_{i} A_{i} \exp \left(-\left(\frac{2\left(q-b_{i}\right)}{c_{i}}\right)^{2} \log (2)\right)+ \\
A_{i} \frac{1-S_{i}}{1+\left(2\left(\frac{q-b_{i}}{c_{i}}\right)\right)}
\end{array}\right\}+B
$$

where $A$ and $A_{i}$ are scale parameters, $S_{i}$ are peak shape parameter, $b_{i}$ are peak positions, and $c_{i}$ are peak widths.

Single-crystal XRD. X-ray data were collected at ambient conditions on a Bruker Smart instrument equipped with an APEX II CCD area detector fixed at a distance of $5.0 \mathrm{~cm}$ from the crystal and a Cu Ka fine focus sealed tube $(1.54178 \AA$ ) operated at $1.5 \mathrm{~kW}(50 \mathrm{kV}, 30 \mathrm{~mA})$, filtered with a graphite monochromator. Diffraction data were processed with Bruker Apex II software suite. The structures were solved with direct methods (SIR92) and subsequent refinements were performed using ShelXle34. MeIm was crystallized from water in its iodide form. Crystallographic information for compounds 10-14 were shown in Supplementary Tables 2 and 3. The crystallographic data (CCDC 1852658-1852662) can be obtained free of charge from The Cambridge Crystallographic Data Centre via www.ccdc.cam.ac. $\mathrm{uk} /$ getstructures.
DFT calculations. Structures of compound 8-14 and ESP were performed using B3LYP DFT under Gaussian G0933. The Polarizable Continuum Model implemented in G09 used an Integral Equation Formalism with water as solvent $(\varepsilon=$ 78.36). All structures were pre-optimized using 6-31 G(d) basis set and refined with $6-311++\mathrm{G}(2 \mathrm{~d}, 2 \mathrm{p})$ basis set, tight convergence criteria. The following contains the coordinates of the model compounds (Supplementary Tables 4-10).

FC analyses. Catalyst loadings of $0.5 \mathrm{mg}_{\mathrm{Pt}} \mathrm{cm}^{-2}$ were used in both anode (PtRu) and cathode $(\mathrm{Pt})$ electrodes. The electrodes, coated onto Toray 60 gas diffusion layers, were placed on opposite sides of the PAImBB(14) AAEM and loaded into FC hardware with a $5 \mathrm{~cm}^{2}$ active area. The cell was tested using a Scribner 850e FC test station. After the AEMFC was assembled, the cell was initially brought to $60^{\circ} \mathrm{C}$ and humidified.

Water electrolysis. Catalyst-coated membranes were prepared using the poly (arylimidazoliums) as the membrane and as ionomer in the catalyst layer. Catalys inks contained $1 \%$ solid, $15-20 \%$ ionomer, $85-80 \%$ Pt on C (46.4\% Pt, Tanaka). The electrolysis cell consisted of a membrane electrode assembly compressed between two titanium bipolar plates having serpentine flow fields. Titanium porous transport layers separated the catalyst layers from the flow fields and provided electrical contact, and allowed transport of gasses and liquid. The bipolar plates were housed in titanium hardware equipped with gold current collectors. Liquid was fed to the anode and cathode using peristaltic pumps at a rate of $10.0 \mathrm{~mL}$ $\min ^{-1}$ and recirculated using liquid gas separators.

\section{Data availability}

The data that support the plots within this paper and other findings of this study are available from the corresponding authors upon reasonable request.

Received: 9 November 2018 Accepted: 25 April 2019

Published online: 24 May 2019

\section{References}

1. Ziv, N., Mustain, W. E. \& Dekel, D. R. The effect of ambient carbon dioxide on anion-exchange membrane fuel cells. ChemSusChem 11, 1136-1150 (2018).

2. Kreuer, K.-D. Ion conducting membranes for fuel cells and other electrochemical devices. Chem. Mater. 26, 361-380 (2013).

3. Noonan, K. J. et al. Phosphonium-functionalized polyethylene: a new class of base-stable alkaline anion exchange membranes. J. Am. Chem. Soc. 134, 18161-18164 (2012)

4. Cho, M. K. et al. Alkaline anion exchange membrane water electrolysis: Effects of electrolyte feed method and electrode binder content. J. Power Sources 382, 22-29 (2018).

5. Wang, L., Bellini, M., Miller, H. A. \& Varcoe, J. R. A high conductivity ultrathin anion-exchange membrane with $500+\mathrm{h}$ alkali stability for use in alkaline membrane fuel cells that can achieve $2 \mathrm{~W} \mathrm{~cm}-2$ at $80^{\circ} \mathrm{C}$. J. Mater. Chem. A 6, 15404-15412 (2018).

6. Diaz, L. A., Lister, T. E., Rae, C. \& Wood, N. D. Anion exchange membrane electrolyzers as alternative for upgrading of biomass-derived molecules. ACS Sustain. Chem. Eng. 6, 8458-8467 (2018).

7. Marinkas, A. et al. Anion-conductive membranes based on 2-mesitylbenzimidazolium functionalised poly(2,6-dimethyl-1,4-phenylene oxide) and their use in alkaline water electrolysis. Polymer 145, 242-251 (2018).

8. Park, J. H. et al. Anion-exchange-membrane-based electrochemical synthesis of ammonia as a carrier of hydrogen energy. Korean J. Chem. Eng. 35, 1620-1625 (2018)

9. Chang, J. et al. Application of anion exchange membrane and the effect of its properties on asymmetric membrane capacitive deionization. Sep. Purif. Technol. 207, 387-395 (2018).

10. Weekes, D. M., Salvatore, D. A., Reyes, A., Huang, A. \& Berlinguette, C. P. Electrolytic CO2 reduction in a flow cell. Acc. Chem. Res. 51, 910-918 (2018).

11. Chavan, V., Agarwal, C., Adya, V. C. \& Pandey, A. K. Hybrid organicinorganic anion-exchange pore-filled membranes for the recovery of nitric acid from highly acidic aqueous waste streams. Water Res. 133, 87-98 (2018).

12. Kim, J.-H., Kim, H.-K., Hwang, K.-T. \& Lee, J.-Y. Performance of airbreathing direct methanol fuel cell with anion-exchange membrane. Int. J. Hydrog. Energy 35, 768-773 (2010).

13. Krol, J. J., Wessling, M. \& Schibli, E. M. Concentration polarization with monopolar ion exchange membranes: current \pm voltage curves and water dissociation. J. Membr. Sci. 162, 145-154 (1999).

14. Gellett, W., Schumacher, J., Kesmez, M., Le, D. \& Minteer, S. D. High current density air-breathing laccase biocathode. J. Electrochem. Soc. 157, B577-B562 (2010). 
15. Gottesfeld, S. et al. Anion exchange membrane fuel cells: current status and remaining challenges. J. Power Sources 375, 170-184 (2018).

16. Pan, J., Chen, C., Zhuang, L. \& Lu, J. Designing advanced alkaline polymer electrolytes for fuel cell applications. Acc. Chem. Res. 45, 473-481 (2012).

17. Varcoe, J. R. et al. Anion-exchange membranes in electrochemical energy systems. Energy Environ. Sci. 7, 3135-3191 (2014).

18. Merle, G., Wessling, M. \& Nijmeijer, K. Anion exchange membranes for alkaline fuel cells: a review. J. Membr. Sci. 377, 1-35 (2011).

19. Marino, M. G. \& Kreuer, K. D. Alkaline stability of quaternary ammonium cations for alkaline fuel cell membranes and ionic liquids. ChemSusChem 8 , 513-523 (2015).

20. Thomas, O. D., Soo, K. J., Peckham, T. J., Kulkarni, M. P. \& Holdcroft, S. A stable hydroxide-conducting polymer. J. Am. Chem. Soc. 134, 10753-10756 (2012).

21. Wright, A. G. \& Holdcroft, S. Hydroxide-stable ionenes. ACS Macro Lett. 3, 444-447 (2014).

22. Wright, A. G. et al. Hexamethyl-p-terphenyl poly(benzimidazolium): a universal hydroxide-conducting polymer for energy conversion devices. Energy Environ. Sci. 9, 2130-2142 (2016).

23. Hugar, K. M., Kostalik, H. A. T. \& Coates, G. W. Imidazolium cations with exceptional alkaline stability: a systematic study of structure-stability relationships. J. Am. Chem. Soc. 137, 8730-8737 (2015).

24. Fan, J. et al. Cationic polyelectrolytes, stable in $10 \mathrm{M} \mathrm{KOHaq}$ at $100^{\circ} \mathrm{C}$. ACS Macro Lett. 6, 1089-1093 (2017).

25. Long, H., Kim, K. \& Pivovar, B. S. Hydroxide degradation pathways for substituted trimethylammonium cations: a DFT study. J. Phys. Chem. C. 116, 9419-9426 (2012).

26. Hibbs, M. R. Alkaline stability of poly(phenylene)-based anion exchange membranes with various cations. J. Polym. Sci. Part B Polym. Phys. 51, 1736-1742 (2013).

27. Wright, A. G., Weissbach, T. \& Holdcroft, S. Poly(phenylene) and mTerphenyl as powerful protecting groups for the preparation of stable organic hydroxides. Angew. Chem. Int. Ed. 55, 4818-4821 (2016).

28. Dekel, D. R., Rasin, I. G., Page, M. \& Brandon, S. Steady state and transient simulation of anion exchange membrane fuel cells. J. Power Sources 375, 191-204 (2018).

29. Dekel, D. R. Review of cell performance in anion exchange membrane fuel cells. J. Power Sources 375, 158-169 (2018).

30. Dekel, D. R. et al. The critical relation between chemical stability of cations and water in anion exchange membrane fuel cells environment. J. Power Sources 375, 351-360 (2018).

31. Diesendruck, C. E. \& Dekel, D. R. Water - a key parameter in the stability of anion exchange membrane fuel cells. Curr. Opin. Electrochem. 9, 173-178 (2018).

32. Dekel, D. R. et al. Effect of water on the stability of quaternary ammonium groups for anion exchange membrane fuel cell applications. Chem. Mater. 29, 4425-4431 (2017).

33. Ahmed Mahmoud, A. M. \& Miyatake, K. Optimization of the pendant chain length in partially fluorinated aromatic anion exchange membranes for alkaline fuel cells. J. Mater. Chem. A 6, 14400-14409 (2018).

34. Li, N., Leng, Y., Hickner, M. A. \& Wang, C.-Y. Highly stable, anion conductive, comb-shaped copolymers for alkaline fuel cells. J. Am. Chem. Soc. 135, 10124-10133 (2013).

35. Schibli, E. M., Wright, A. G., Holdcroft, S. \& Frisken, B. J. Morphology of anion-conducting ionenes investigated by $\mathrm{X}$-ray scattering and simulation. J. Phys. Chem. B 122, 1730-1737 (2018).

36. Gostick, J. T. \& Weber, A. Z. Resistor-network modeling of ionic conduction in polymer electrolytes. Electrochim. Acta 179, 137-145 (2015).

37. Maalouf, M. et al. Factors enabling high mobility of protons and water in perfluorosulfonate membranes under low hydration conditions1. Int. J. Hydrog. Energy 39, 2795-2800 (2014).

38. Kreuer, K. D. et al. Short-side-chain proton conducting perfluorosulfonic acid ionomers: why they perform better in PEM fuel cells. J. Power Sources 178, 499-509 (2008).

39. Eikerling, M. H. \& Berg, P. Poroelectroelastic theory of water sorption and swelling in polymer electrolyte membranes. Soft Matter 7, 5976-5990 (2011).
40. Giffin, G. A., Haugen, G. M., Hamrock, S. J. \& Di Noto, V. Interplay between structure and relaxations in perfluorosulfonic acid proton conducting membranes. J. Am. Chem. Soc. 135, 822-834 (2013).

41. Omasta, T. J. et al. Strategies for reducing the PGM loading in high power AEMFC anodes. J. Electrochem. Soc. 165, F710-F717 (2018).

42. Su, H., Bladergroen, B. J., Linkov, V., Pasupathi, S. \& Ji, S. Study of catalyst sprayed membrane under irradiation method to prepare high performance membrane electrode assemblies for solid polymer electrolyte water electrolysis. Int. J. Hydrog. Energy 36, 15081-15088 (2011).

43. Strmcnik, D. et al. When small is big: the role of impurities in electrocatalysis. Top. Catal. 58, 1174-1180 (2015).

\section{Acknowledgements}

This research was conducted as part of the Engineered Nickel Catalysts for Electrochemical Clean Energy project and supported by Grant Number RGPNM 477963-2015 under the Natural Sciences and Engineering Research Council of Canada (NSERC) Discovery Frontiers Program. This work was partially financially supported by the Discovery Grants Program, NSERC [Grant RGPIN-2018-03698]; by the European Union's Horizon 2020 research and innovation program [grant number 721065]; by the Ministry of Science, Technology \& Space of Israel [grant number 3-12948]; by the Israel Science Foundation (ISF) [grant number 1481/17]; by the Israel Innovation Authority through the KAMIN program [grant number 60503]; and by the Ministry of National Infrastructure, Energy and Water Resources of Israel [grant number 3-13671]. Computing resources were provided by West-Grid (www.westgrid.ca) and Compute Canada (www.computecanada.ca). We thank Mr. Jonathan Ward and Drs. Timothy Peckham and Benjamin Britton of Simon Fraser University for useful discussions.

\section{Author contributions}

S.H. and J.F. generated the main ideas for the project and wrote most of the text of this paper. J.F. carried out the majority of the syntheses and chemical characterization, DFT calculations, and conductivity and degradation measurements. S.W.C., C.E.D., and D.R.D. carried out degradation analyses under low lambda conditions and contributed ideas and interpretation. Z.P., W.L., and T.J.G.S. assisted in syntheses. A.T.S. carried out crystal structure analyses. E.M.S. and B.J.F. acquired and interpreted scattering data. E.M. and W.E.M. carried out FC testing. A.H. carried out electrolyzer testing.

\section{Additional information}

Supplementary Information accompanies this paper at https://doi.org/10.1038/s41467 019-10292-z.

Competing interests: The authors declare no competing interests.

Reprints and permission information is available online at http://npg.nature.com/ reprintsandpermissions/

Journal peer review information: Nature Communications thanks the anonymous reviewers for their contribution to the peer review of this work.

Publisher's note: Springer Nature remains neutral with regard to jurisdictional claims in published maps and institutional affiliations.

Open Access This article is licensed under a Creative Commons Attribution 4.0 International License, which permits use, sharing, adaptation, distribution and reproduction in any medium or format, as long as you give appropriate credit to the original author(s) and the source, provide a link to the Creative Commons license, and indicate if changes were made. The images or other third party material in this article are included in the article's Creative Commons license, unless indicated otherwise in a credit line to the material. If material is not included in the article's Creative Commons license and your intended use is not permitted by statutory regulation or exceeds the permitted use, you will need to obtain permission directly from the copyright holder. To view a copy of this license, visit http://creativecommons.org/ licenses/by/4.0/.

(C) The Author(s) 2019 